\title{
Regionally-derived cell populations and skeletal stem cells from human foetal femora exhibit specific osteochondral and multi-lineage differentiation capacity in vitro and ex vivo
}

David Gothard ${ }^{1 *}$, Kelvin Cheung ${ }^{1}$, Janos M. Kanczler ${ }^{1}$, David I. Wilson ${ }^{2,3}$ and Richard O. C. Oreffo ${ }^{\text {** }}$

\begin{abstract}
Background: Adult skeletal stem cells (SSCs) often exhibit limited in vitro expansion with undesirable phenotypic changes and loss of differentiation capacity. Foetal tissues offer an alternative cell source, providing SSCs which exhibit desirable differentiation capacity over prolonged periods, ideal for extensive in vitro and ex vivo investigation of fundamental bone biology and skeletal development.

Methods: We have examined the derivation of distinct cell populations from human foetal femora. Regionally isolated populations including epiphyseal and diaphyseal cells were carefully dissected. Expression of the SSC marker Stro-1 was also found in human foetal femora over a range of developmental stages and subsequently utilised for immuno-selection.

Results: Regional populations exhibited chondrogenic (epiphyseal) and osteogenic (diaphyseal) phenotypes following in vitro and ex vivo characterisation and molecular analysis, indicative of native SSC maturation during skeletal development. However, each population exhibited potential for induced multi-lineage differentiation towards bone (bone nodule formation), cartilage (proteoglycan and mucopolysaccharide deposition) and fat (lipid deposition), suggesting the presence of a shared stem cell sub-population. This shared sub-population may be comprised of Stro-1+ cells, which were later identified and immuno-selected from whole foetal femora exhibiting multi-lineage differentiation capacity in vitro and ex vivo.
\end{abstract}

Conclusions: Distinct populations were isolated from human foetal femora expressing osteochondral differentiation capacity. Stro-1 immuno-selected SSCs were isolated from whole femora expressing desirable multi-lineage differentiation capacity over prolonged in vitro expansion, superior to their adult-derived counterparts, providing a valuable cell source with which to study bone biology and skeletal development.

Keywords: Adipogenesis, Bone, Chondrogenesis, Development, Diaphysis, Epiphysis, Human foetal femur, Osteogenesis, Stro-1

\footnotetext{
* Correspondence: d.gothard@hotmail.co.uk; roco@soton.ac.uk

${ }^{1}$ Bone and Joint Research Group, Centre for Human Development, Stem Cells and Regeneration, Human Development and Health, University of Southampton, School of Medicine, Institute of DevelopmentalSciences, Mail Point 887, Southampton General Hospital, Tremona Road, Southampton

SO16 6YD, UK

Full list of author information is available at the end of the article
} 


\section{Background}

Bone damage and loss due to disease and trauma is a growing concern for an increasingly aged population. Many methods exist to repair bone defects including auto- and allografts, and de novo tissue engineering [1-4]. However, a major limitation of reparative strategies is fully understanding the biological mechanisms controlling skeletal development. Elucidation of native development and healing would inevitably improve successful bone defect treatment, whether by reparation, replacement or regeneration. To investigate basic human bone biology and understand the fundamental mechanisms of bone formation and repair, a robust in vitro/ex vivo developmental paradigm representative of native skeletal development is required. A critical step in this approach is the identification and isolation of osteoprogenitor cells capable of osteochondral differentiation to inform bone regeneration and augmentation [5-7]. Furthermore, a homogeneous bone stem cell population would enable interrogation of skeletal development and aid screening for reparative strategies, including osteoconductive scaffolds and osteoinductive signalling molecules and mechanical cues $[8,9]$.

Adult human bone marrow stromal cells (HBMSCs) contain a diminutive bone stem cell population ( 1 in 10,000 to 50,000 ) often referred to as mesenchymal stem cells (MSCs), which exhibit osteochondral differentiation capacity [10-12]. MSCs have been shown in a number of studies to generate tissues of the in vivo musculoskeletal system including bone, cartilage, fat, ligament, muscle and tendon [10, 13-17]. However, conventional MSC populations are highly heterogeneous and controversy over their exact identity and differentiation potential remains with reports of hepatocyte and neuronal differentiation $[18,19]$. The observed heterogeneity $[20,21]$ is likely a consequence of their derivation from a multitude of adult tissues including dental pulp, fat, muscle, skin, synovium [22-27], and extra-embryonic tissues including amniotic fluid, placenta and umbilical cord blood [28-31]. This highlights the need for robust in vitro clonal analysis and in vivo validation of exact differentiation capacity. The exact phenotype is more than scientific pedantry as heterogeneity impacts on MSC suitability for clinical application, demanding an additional purification step either before controlled differentiation (isolation of a homogeneous stem cell population) [6] or following heterogeneous differentiation (isolation of specific terminally differentiated cell types) [32]. Given the imprecise nature and often misappropriate use of the term MSC (typically almost any adherent fibroblastic cell population, as well as the observation that MSCs from different tissues are not the same), we have used the term skeletal stem cell (SSC) [2, 33-35] in reference to the stem cell population with specific differentiation capacity (haematopoietic supportive stroma) towards all skeletal tissues including bone, cartilage, and fat [9, 36-38].

An alternative cell source to adult tissue, yet controversial, is foetal tissue which has been shown to contain cell populations with comparable if not enhanced reparative function [39-42]. Foetal femora are composed of proliferative osteochondral progenitor cells capable of self-renewal, differentiation and bone and cartilage formation. During development, these populations exhibit regional differences driving endochondral ossification and formation of long bones. The epiphyseal region is predominantly cartilaginous, whilst the diaphyseal region undergoes mineralisation and bone formation. Cell populations isolated from these separate regions would help delineate the sequential biological mechanisms driving bone formation and inform efforts to improve bone repair and regeneration. As in adult tissues, foetal SSCs constitute osteochondral progenitors capable of cartilage and bone formation, and the authors hypothesise that both epiphyseal and diaphyseal populations share this SSC sub-population.

One surface marker which has shown robust enrichment specificity for SSCs is trypsin-resistant cell surface antigen 1 (Stro-1) [43-46]. Adult Stro-1+ populations exhibit enhanced colony forming unit-fibroblastic (CFU-F) capacity and elevated osteogenic differentiation both in vitro and in vivo in comparison to unsorted adult HBMSCs [47-50]. Consequently, Stro-1 expression was sought in human foetal femora to identify possible foetal SSCs. Previous work has shown that whole foetal femur-derived cell populations offer an alternative to adult populations, specifically for in vitro investigation of human skeletal development, displaying significantly enhanced proliferation and multilineage differentiation capacity [5, 51-55]. Furthermore, studies have demonstrated significant enhancement of bone defect repair following application of whole foetal femur-derived cell populations in biodegradable carrier scaffolds [56-59].

The current study has isolated and characterised a Stro$1+$ sub-population in whole foetal femora, representing foetal femur-derived SSCs. Specifically, we have examined the potential of foetal femur tissue as a source of inducible SSCs, built on the premise that distinct regional cell populations could be routinely derived exhibiting specific chondrogenic and osteogenic differentiation capacity, and that Stro-1 enrichment could target a SSC sub-population. These populations could provide the necessary in vitro/ ex vivo investigative tools to elucidate bone biology mechanisms active during skeletal development.

\section{Methods}

All tissue culture reagents, growth factors, chemicals and other materials were supplied by Sigma Aldrich unless otherwise stated. Collagen type I polyclonal antibody was a kind gift from Dr. Larry Fisher (National Institutes of 
Health (NIH)). Hydroxyapatite-loaded poly-lactic acid scaffolds (HA-PLA) were kindly provided by Dr. Lisa White, University of Nottingham. Stro-1 hybridoma was re-derived from an original donation provided by Dr. Jon N. Beresford, University of Bath [44, 60]. Fertilized chicken eggs were supplied by Henry Stewart \& Co. Ltd, Fakenham, Norfolk, NR21 8LZ, United Kingdom.

\section{Ethics statement}

Foetal tissue was obtained following informed consent and ethical approval from the National Research Ethics Committee South Central-Southampton (REC 296/00296100). All animal procedures were carried out in accordance with the guidelines and regulations laid down in the Animals (Scientific Procedures) Act 1986. As part of the application for a project licence under which to perform the animal work, animal procedures in this study were reviewed and approved by the Scientific Review Group, part of the Animal Welfare and Ethical Review Body at the University of Southampton. Chick embryos were sacrificed at embryonic day 11 by schedule 1 decapitation according to Home Office Approval UK (Project license - PPL 30/2762). Femora were dissected from embryonic day 11 chick embryos (Gallus domesticus), and soft tissue was carefully removed.

\section{Cell isolation and culture}

\section{Human foetal femur preparation}

Femora were obtained following termination of pregnancy and informed patient consent. Foetal age was determined according to foot length and expressed as days post-conception. Samples ranged from 53 to 69 days (4 $\mathrm{mm}$ to $8.5 \mathrm{~mm})[5,61]$. Femora were dissected and surrounding soft tissues were removed by gentle rolling back and forth across sterile filter paper. Soft tissues stuck to the filter paper whilst the femur was separated cleanly. Dependent on the developmental stage of each sample, the periosteum was removed manually by dissection (older samples) or as part of the preparation procedure (younger samples).

\section{Epiphyseal and diaphyseal cell isolation}

Prepared femora were dissected into epiphyseal and diaphyseal regions via a transverse incision through the metaphysis region at either end of the bone collar (Additional file 1: Figure S1). The bone collar distinguished the boundary between the diaphysis and epiphyses. Both proximal and distal epiphyses were combined in each sample and carefully cut into small segments, as was the diaphysis separately, prior to overnight collagenase B (Roche Products Limited (Pharmaceuticals), Welwyn Garden City, AL7 1TW, United Kingdom) digestion ( $1 \mathrm{mg} / \mathrm{mL}$ in minimum essential medium - alpha [ $\alpha$-MEM, Life Technologies Ltd, Thermo Fisher Scientific, Paisley, PA4 9RF, United Kingdom]) at $37^{\circ} \mathrm{C}$. Isolated cells were cultured in basal medium.

\section{SSC isolation}

Whole femora were cut into small segments and collagenase B digested overnight in preparation for Stro-1 immuno-selection. Most of the tissue was completely digested, however, individual isolated cells were passed through a $40 \mu \mathrm{m}$ sieve (BD Biosciences, Oxford Science Park, Oxford OX4 4DQ, United Kingdom) to remove large clumps and mineralised bone collar, and suspended in basal medium ( $\alpha$-MEM, $10 \%$ foetal calf serum (FCS, Invitrogen, Thermo Fisher Scientific, Paisley, PA4 9RF, United Kingdom), penicillin (100 U/mL, PAA Laboratories Ltd, Yeovil, Somerset, BA22 8YG, United Kingdom), and streptomycin $(0.1 \mathrm{mg} / \mathrm{mL}$, PAA Laboratories Ltd, Yeovil, Somerset, BA22 8YG, United Kingdom)). Cells were initially incubated with blocking buffer ( $\alpha$-MEM, $10 \%$ human serum, $5 \%$ FCS and $1 \%$ bovine serum albumin (BSA, PAA Laboratories Ltd, Yeovil, Somerset, BA22 8YG, United Kingdom)) before incubation with primary Stro-1 antibody (undiluted hybridoma culture supernatant) [62]. Suspensions were subsequently washed three times in isolation buffer $(2 \mathrm{mM}$ ethylenediaminetetraacetic acid [EDTA] and $1 \% \mathrm{BSA}$ in phosphate buffered saline [PBS]) before incubation with magnetic beadconjugated secondary antibody $(200 \mu \mathrm{L}$ in $1 \mathrm{~mL}$ isolation buffer, Miltenyi Biotec Ltd, Woking, Surrey GU24 9DR, United Kingdom). Samples were then washed and target cells isolated by magnetic-activated cell sorting (MACS) prior to suspension and culture in basal medium.

\section{Adult SSC isolation}

Adult Stro-1 populations were isolated as detailed above. In brief, bone marrow was isolated from haematologically normal osteoarthritic patients undergoing total hip replacement at the Southampton General Hospital with informed consent (approval from the Southampton and South West Hampshire Local Research Ethics Committee [LREC194/99]). Bone marrow was sieved to remove blood clots and bone fragments and treated with a density gradient solution (Lymphoprep ${ }^{\mathrm{Tw}}$, Lonza, Slough, Berkshire, SL1 4DX, United Kingdom) to remove erythrocytes. The remaining cell suspension was then immuno-labelled with Stro-1 and sorted by MACS. Control unsorted cell populations were separated from each sample before Stro-1 antibody labelling. Unsorted cells were processed in parallel in PBS. Isolated cell populations were suspended and cultured in basal medium.

\section{Cell characterisation}

\section{Alkaline phosphatase expression}

Cultures (P1) were PBS washed $3 \mathrm{~h}$ after seeding into culture flasks to remove non-adhered cells, and incubated for 14 days without basal medium change at $37{ }^{\circ} \mathrm{C}$, $5 \% \mathrm{CO}_{2}$ in a humidified atmosphere. Cultures were fixed with $85 \%$ ethanol before air drying then incubation with 
Fast Violet B salt $(2.5 \mu \mathrm{g} / \mathrm{mL})$ and Naphthol AS-MX phosphate $(40 \mu \mathrm{L} / \mathrm{mL})$ in $\mathrm{dH}_{2} \mathrm{O}$ for $30-45 \mathrm{~min}$ at $37{ }^{\circ} \mathrm{C}$ and $5 \% \mathrm{CO}_{2}$ in a humidified atmosphere under dark conditions. Cultures were then washed with $\mathrm{H}_{2} \mathrm{O}$ and counterstained in haematoxylin for $5 \mathrm{~min}$. Cultures were washed with $\mathrm{H}_{2} \mathrm{O}$ again and left to air dry prior to quantification.

Seeding densities were selected based on whether clear colonies could be observed following qualitative assessment of a series of seeding densities including $0.5 \times 10^{1}$, $1 \times 10^{1}, 1 \times 10^{2}$, and $1 \times 10^{3}$ cells $/ \mathrm{cm}^{2}$.

\section{Specific alkaline phosphatase activity}

Samples were fixed in $85 \%$ ethanol before treatment with $0.05 \%$ Triton $^{\text {Tm }}$ X-100 and three freeze-thaw cycles. DNA quantification was assessed by diluting cell lysate with Tris/EDTA buffer and addition of Quant-iT ${ }^{\mathrm{Tm}}$ PicoGreen $^{\circ}$ dsDNA reagent (Life Technologies). Alkaline phosphatase (ALP) activity was assessed by diluting cell lysate in ALP substrate solution $(2 \mathrm{mg} / \mathrm{mL}$ p-nitrophenyl phosphate [pNPP] in $0.75 \mathrm{M}$ alkaline buffer solution). Samples were then incubated at $37{ }^{\circ} \mathrm{C}$ in the dark, under gentle agitation, and the reaction was terminated with $1 \mathrm{M}$ sodium hydroxide after 45-60 min. Spectrophotometry was used to quantify DNA and ALP activity at $530 \mathrm{~nm}$ and $405 \mathrm{~nm}$, respectively. ALP concentration was measured in nmol $\mathrm{pNPP} / \mathrm{mL} \mathrm{h}-1$, and ALP activity in nmol $\mathrm{pNPP} / \mu \mathrm{g}$ DNA.

\section{Differentiation culture - monolayer/micromass \\ Osteogenesis}

Cells (P2) were seeded at $1 \times 10^{3} \mathrm{cell} / \mathrm{cm}^{2}$ and cultured in osteogenic medium ( $\alpha$-MEM, $10 \%$ FCS, $10 \mathrm{nM}$ dexamethasone [Dex] and $100 \mu \mathrm{M}$ ascorbate-2-phosphate [Asc]) for 14 days. Osteogenic medium was supplemented with $10 \mathrm{mM} \beta$-glycerophosphate to enable bone nodule formation. Cultures were fixed in $4 \%$ paraformaldehyde (PFA) and stained with Alizarin red $\left(1 \% \mathrm{w} / \mathrm{v}\right.$ in $\left.\mathrm{dH}_{2} \mathrm{O}\right)$.

\section{Chondrogenesis}

A total of $2.5 \times 10^{5}$ cells (P2) per micromass were suspended in 10-20 $\mu \mathrm{L}$ basal medium, pipetted carefully into a six-well plate and incubated for $1 \mathrm{~h}$ allowing attachment to the plate and cell/cell adhesion. Basal medium was removed and chondrogenic medium ( $\alpha$-MEM, $10 \mathrm{nM}$ Dex, $100 \mu \mathrm{M}$ Asc, $10 \mathrm{ng} / \mathrm{mL}$ TGF $\beta$-3 [Peprotech, London, W6 8LL, United Kingdom]) and $10 \mu \mathrm{g} / \mathrm{mL}$ insulin (in the form of $100 \times$ insulin/tranferrin/sodium selenite [ITS] solution) was carefully added so as to not disturb the micromass. After 21 days, cultures were fixed in $4 \%$ PFA and stained with Alcian blue $\left(0.5 \% \mathrm{w} / \mathrm{v}\right.$ in acidic $\mathrm{H}_{2} \mathrm{O}[0.01 \%$ acetic acid]).

\section{Adipogenesis}

Cells (P2) were seeded at $1 \times 10^{3} \mathrm{cell} / \mathrm{cm}^{2}$ and cultured in adipogenic medium ( $\alpha$-MEM, $10 \%$ FCS, $1 \mu \mathrm{M}$ Dex,
$0.5 \mathrm{mM}$ 3-isobutyl-1-methylxanthine [IBMX], $100 \mu \mathrm{M}$ indomethacin and $10 \mu \mathrm{g} / \mathrm{mL}$ ITS solution) for three days followed by one day in ITS only medium ( $\alpha$-MEM, $10 \%$ FCS and $10 \mu \mathrm{g} / \mathrm{mL}$ ITS solution). This was repeated three times before continuous culture in ITS medium up to 28 days. Cultures were fixed in Baker's formal calcium $(0.1 \mathrm{~g} / \mathrm{mL}$ calcium chloride in $4 \%$ formaldehyde), rinsed with $60 \%$ isopropanol, and stained with a filtered working solution $\left(3: 2\right.$ in $\left.\mathrm{dH}_{2} \mathrm{O}\right)$ of stock Oil Red $\mathrm{O}$ (powder saturated $99 \%$ isopropanol) for $15 \mathrm{~min}$. Alternative adipogenic medium ( $\alpha$-MEM, $10 \%$ FCS, $100 \mathrm{nM}$ Dex, $0.5 \mathrm{mM}$ IBMX, $3 \mu \mathrm{g} / \mathrm{mL}$ ITS solution and $1 \mu \mathrm{M}$ rosiglitazone) was utilised for later differentiation cultures. Revised adipogenic medium was observed to induce lipid formation within 14 days.

All cultures received medium changes twice weekly. All differentiation media were not supplemented with penicillin and streptomycin. Following revised adipogenic medium, all diaphyseal and epiphyseal differentiation cultures were revised to a total 14 day culture period.

\section{D pellet formation and organotypic culture}

Epiphyseal and diaphyseal populations were cultured as pellets $\left(2.5 \times 10^{5}\right.$ cells per pellet [P2]) in basal medium for $48 \mathrm{~h}$ to allow formation before transfer to organotypic culture on polytetrafluoroethylene (PTFE) confetti membranes (BioCell Interface, La Chaux-de-Fonds, Switzerland) on tissue culture flask-well inserts. Organotypic pellets were cultured for 21 days in either basal, osteogenic or chondrogenic medium (detailed previously). After 21 days, pellets were processed and assessed for ALP activity as described previously.

\section{Histomorphometry analysis}

Following differentiation culture and histological staining, three or five representative images (unsorted vs Stro-1, and epiphyseal vs diaphyseal, respectively) across each sample well (triplicate wells) were used to quantify differentiation. CellProfiler image software was employed to quantify the area $\left(\mathrm{cm}^{2}\right)$ of stain per $10^{5}$ cells (cell nuclei were counterstained with DAPI and imaged by fluorescence microscopy). Following micromass culture in chondrogenic medium, histological staining and imaging, Fiji (Image J) image software was used to quantify mean colour intensity in individual micromass pellets (triplicate wells per sample: one to three micromass pellets per well, epiphyseal vs diaphyseal, and unsorted vs Stro-1, respectively). Colour quantification was achieved through greyscale conversion and assessment of mean intensity across the diameter of the micromass pellet ( 0 to 255 scale; black through to white): values were inverted so 0 was white and 255 was black. 


\section{Molecular analysis}

MirVana $^{\text {as }}$ RNA Isolation System Kit (Life Technologies) was used for RNA extraction according to the manufacturer's protocol following 14 days culture in basal conditions. Cultured samples were placed on ice and washed twice in PBS. Lysis buffer and a homogenizing agent were used to liberate RNA from cells, followed by acid phenolchloroform. The resultant mixture was centrifuged to allow phase separation. The RNA-containing aqueous phase was removed and added to ethanol prior to elution through a spin column. The column was washed three times with supplied buffer solutions and RNA eluted in RNase free water.

For cDNA synthesis, SuperScript ${ }^{\circ}$ VILO cDNA Synthesis Kit (Life Technologies) was used for cDNA synthesis. RNA was combined with $5 \mathrm{x}$ VILO $^{\mathrm{m}}$ reaction mix and $1 \mu \mathrm{L}$ of 10x SuperScript ${ }^{\circ}$ enzyme was added to RNA samples and incubated at $25{ }^{\circ} \mathrm{C}$ for $10 \mathrm{~min}$ followed by $42{ }^{\circ} \mathrm{C}$ for $2 \mathrm{hr}$. The reaction was terminated by incubation at $85{ }^{\circ} \mathrm{C}$ for 5 min. Then, $40 \mu \mathrm{L}$ of ultra-pure $\mathrm{H}_{2} \mathrm{O}\left(\mathrm{upH}_{2} \mathrm{O}\right)$ was added to the cDNA sample to give a 1:4 dilution and stored at $-20{ }^{\circ} \mathrm{C}$ or used immediately for quantitative RT-qPCR analysis. Quantitative RT-qPCR was performed using SYBR-Green PCR master mix (Life Technologies): $10 \mu \mathrm{L}$ of SYBR-Green master mix; $5 \mu \mathrm{L}$ of $\mathrm{upH}_{2} \mathrm{O} ; 2 \mu \mathrm{L}$ of forward and reverse primers for the gene of interest (Additional file 2: Table S1) and $1 \mu \mathrm{L}$ of cDNA sample. The final mixture $(20 \mu \mathrm{L})$ was added to each well of a 96-well-plate, analyzed using an Applied Biosystem (Life Technologies), 7500 Real Time PCR system. Data generated by RT-qPCR were analysed using the Applied Biosystem 7500 System SDS Software, version 2.0.5. Ct value (cycle threshold) for each sample was normalized to $\beta$ actin, an endogenous housekeeping gene, and fold expression levels for each target gene were calculated using the delta-delta Ct method.

\section{Ex vivo tissue regeneration Chick femora isolation}

Fertilized eggs were incubated (Hatchmaster, Brinsea Products Ltd, Weston Industrial Estate, Weston Super Mare, BS24 9BG, United Kingdom) for 11 days. Chick embryos were euthanized by decapitation prior to bilateral dissection of femora. Surrounding soft tissue was removed from the femora before overnight incubation in basal medium $[63,64]$.

\section{Defect preparation and 3D pellet implantation}

Following test defects using a $300 \mu \mathrm{m}$ diameter drill (Additional file 3: Figure S2), a diaphyseal defect was positioned centrally along the length of the femur, and epiphyseal defects were positioned halfway between the end of the femur and the end of the bone collar. The femurs continue to grow and the tissues swell during the 10-day culture period contributing to partial closure of the defects. However, the defects are still visible after 10 days without implantation of cell pellets. Drill defects were plugged with appropriate preformed cell pellets $\left(1.5 \times 10^{4}\right.$ cells [P2] per pellet, centrifuged at 1,000 rpm for $4 \mathrm{~min}$, and incubated for $48 \mathrm{~h}$ in basal medium) and cultured organotypically on well inserts for 10 days in $\alpha$-MEM with $100 \mu \mathrm{M}$ Asc. Medium was changed every day before $4 \%$ PFA fixation. A standard curve detailing the correlation between cell number $\left(1 \times 10^{4}, 5 \times 10^{4}, 1 \times 10^{5}, 2.5 \times 10^{5}\right.$, $5 \times 10^{5}$, and $1 \times 10^{6}$ cells) and pellet diameter was used to assess the appropriate cell number required to generate a $300 \mu \mathrm{m}$ diameter pellet (Additional file 4: Figure S3).

Ex vivo chick femur defects offered a simple and relatively rapid model for assessment of differentiation and tissue regeneration capacity inherent to distinct isolated populations. The advantage of the system is that it offers a high throughput skeletal model for screening candidate cell populations prior to expensive and time consuming in vivo models. Previous work in the group has shown that organotypic culture beyond 10 days has detrimental effects on cell viability in the femora. Embryonic day 11 chick femora were selected due to the presence of an osteogenic phenotype dominating the diaphyseal region with bone collar formation, and a chondrogenic phenotype dominating the epiphyseal regions. Both environments were required to assess the osteochondral differentiation capacity of implanted pellets.

\section{Histological analysis \\ Sample preparation and sectioning}

Pellets and organotypic femora were fixed in $4 \%$ PFA for $24 \mathrm{~h}$, dehydrated through a series of ethanol washes (50\%, $70 \%, 90 \%$ in $\mathrm{dH}_{2} \mathrm{O}$, and $2 \times 100 \%, 1 \mathrm{~h}$ in each), and incubated in Histo-Clear (National Diagnostics UK, Unit 4 Fleet Business Park, East Riding of Yorkshire, HU139LX, United Kingdom) for $1 \mathrm{~h}$ prior to paraffin wax at $60{ }^{\circ} \mathrm{C}(1 \mathrm{~h})$. Processed samples were subsequently embedded in wax blocks using an automated Shandon Citadel 2000 ready for histological assessment. Embedded samples were sectioned at a thickness of $7 \mu \mathrm{m}$ using a Microm HM330 D-6900 microtome (Heidelberg Instruments, Tullastraße 2, 69126 Heidelberg, Germany). All sections from pellets and femora were collected. Sections were stained, washed in water, dehydrated where appropriate and mounted with DPX before imaging on an Olympus BX-51/22 dotSlide digital virtual microscope using OlyVIA 2.1 software (Olympus Soft Imaging Solutions GmbH, Johann-Krane-Weg, 3948149 Münster, Germany, GmBH).

\section{Alcian blue/Sirius red}

Slides were de-waxed and rehydrated before treatment with haematoxylin (10 $\mathrm{min})$, followed by acid-alcohol 
dip and treatment with Alcian blue (10 min - $0.5 \%$ w/ v), molybdophosphoric acid (10-20 min $-1 \% \mathrm{w} / \mathrm{v})$ and Sirius red $(45-60 \mathrm{~min}-0.1 \% \mathrm{w} / \mathrm{v}$ in $100 \mathrm{~mL}$ picric acid and $\left.200 \mathrm{~mL} \mathrm{dH}_{2} \mathrm{O}\right)$.

\section{Von Kossa}

Slides were de-waxed and rehydrated before treatment with $1 \%$ silver nitrate under UV irradiation for $20 \mathrm{~min}$. Slides were then treated with $2.5 \%$ sodium thiosulfate ( $8 \mathrm{~min})$ and counterstained with Alcian blue $(1 \mathrm{~min})$ and van Gieson (5 min - $0.9 \mathrm{mg} / \mathrm{mL}$ Acid Fucshin in $50 \%$ Picric acid).

\section{Goldner's Trichrome}

Slides were de-waxed and rehydrated before treatment with haematoxylin $(10 \mathrm{~min})$, followed by acid/alcohol dip. Slides were treated for $5 \mathrm{~min}$ with $10 \% \mathrm{v} / \mathrm{v}$ ponceau-fuchsin $(0.75 \% \mathrm{w} / \mathrm{v}$ and $0.25 \% \mathrm{w} / \mathrm{v}$, respectively, in $1 \%$ acetic acid) and $2 \% \mathrm{v} / \mathrm{v}$ azophloxin solution $(0.5 \% \mathrm{w} / \mathrm{v}$ in $0.6 \%$ acetic acid) in acetic acid $(0.2 \%$ in $\mathrm{dH}_{2} \mathrm{O}$ ). Slides were subsequently treated with $0.6 \% \mathrm{w} / \mathrm{v}$ phosphomolybdic acid and $0.4 \% \mathrm{w} / \mathrm{v}$ orange $\mathrm{G}$ solution in $\mathrm{dH}_{2} \mathrm{O}$ with thymol $(20 \mathrm{~min})$ before counterstaining with $0.2 \% \mathrm{w} / \mathrm{v}$ light green solution in $0.2 \%$ acetic acid. Stained sections were blotted dry and directly mounted with DPX.

\section{Birefringence}

Organotypic femora following Alcian blue/Sirius red (A/S) staining were also imaged using polarising filters to assess birefringence in implanted pellets by light microscopy. Femora were preferentially sectioned in the longitudinal plane to enable defect visualisation in the same section. Sections were oriented to follow the path of the drill defect through the femur to aid implant localisation. Birefringence colour correlated with collagen fibre alignment. Highly aligned collagen fibres in mineralised bone appeared red, whilst less aligned collagen fibres in premineralised bone appeared yellow, and in osteoid appeared green.

\section{Immunochemistry}

Sample sections were de-waxed and rehydrated before hydrogen peroxide $\left(3 \%\right.$ in $\left.\mathrm{dH}_{2} \mathrm{O}\right)$ quenching of endogenous peroxidase activity. Sections were incubated with blocking buffer (1\% BSA in PBS) for 15 min then primary antibody solution (1:1,000 COL1A1 (LF69), 1:500 COL2A1 (Cabiochem, Merck Millipore Ltd, Feltham, Middlesex, TW14 8NX, United Kingdom) and 1:50 SOX9 [Abcam, Cambridge Science Park, Cambridge, CB4 OFL, United Kingdom]) overnight at $4{ }^{\circ} \mathrm{C}$. Biotinylated secondary antibody (1:200 in blocking buffer) was applied for $1 \mathrm{~h}$ before incubation with avidin- conjugated peroxidase. Finally, sections were treated with 3-amino-9-ethylcarbazole for $10 \mathrm{~min}$ until visualisation of a red-brown reaction product [5]. Sections were washed between steps with blocking buffer and mounted with Fluoromount ${ }^{\mathrm{Tm}}$ once stained. Negative controls were run alongside lacking the respective primary antibody before imaging on dotSlide.

\section{Statistical analysis}

A non-parametric Mann Whitney or Wilcoxon test was employed to assess significance between unpaired and paired data sets, respectively. Results are presented as mean \pm SD. Significance is depicted by " $\mathrm{P} \leq 0.05,{ }^{\prime \prime \prime} \mathrm{P} \leq 0.01$, $\mathrm{P} \leq 0.001$.

\section{Results}

Characterisation of foetal femur cell populations isolated by region

2D characterisation of epiphyseal and diaphyseal populations in vitro

Following isolation and in vitro culture, both epiphyseal and diaphyseal populations exhibited similar colony formation capacity (Fig. 1a). However, diaphyseal populations exhibited significantly $(\mathrm{P} \leq 0.05)$ enhanced ALP+ colony formation with an approximate three-fold increase (Fig. 1b).

Basal cultures of epiphyseal and diaphyseal populations were assessed by molecular analysis for a selection of osteochondral genes (Fig. 1). Diaphyseal populations exhibited significantly increased expression of osteogenic genes including RUNX2 (8.4 fold, $\mathrm{P} \leq 0.001$ ), ALP (8.6 fold, $\mathrm{P} \leq 0.001$ ), collagen type 1 (COL1A1, 2.3 fold, $\mathrm{P} \leq$ 0.01 ) and osteonectin (ON, 1.6 fold, $\mathrm{P} \leq 0.01)$ (Fig. 1c to $\mathrm{f}$, respectively). Osterix (OSX) expression appeared greater in diaphyseal populations, although this did not reach significance (Fig. 1g). Osteocalcin (OCN) expression, a late osteogenesis marker, was significantly $(\mathrm{P} \leq 0.01)$ reduced in diaphyseal compared to epiphyseal populations (Fig. 1h). Early chondrogenesis marker expression was significantly reduced in diaphyseal populations for genes including SOX9 (1.5 fold, $\mathrm{P} \leq 0.05)$ and collagen type 2 (COL2A1, 20 fold, $\mathrm{P} \leq 0.01$ ) (Fig. 1i and j). Interestingly, collagen type 10 (COL10A1) expression, a late chondrogenesis marker, was significantly $(\mathrm{P} \leq 0.01)$ increased in diaphyseal populations (Fig. 1k).

High ALP expression in diaphyseal populations correlated with significantly $(\mathrm{P} \leq 0.001)$ increased calcification (Alizarin red stained bone nodule formation) and significantly $(\mathrm{P} \leq 0.001)$ decreased lipid deposition (Oil Red $\mathrm{O}$ stained lipid deposition) (Fig. 2a and b, respectively) following differentiation culture. Cartilaginous matrix formation was also significantly $(\mathrm{P} \leq 0.05)$ decreased in diaphyseal compared to epiphyseal populations (Alcian 


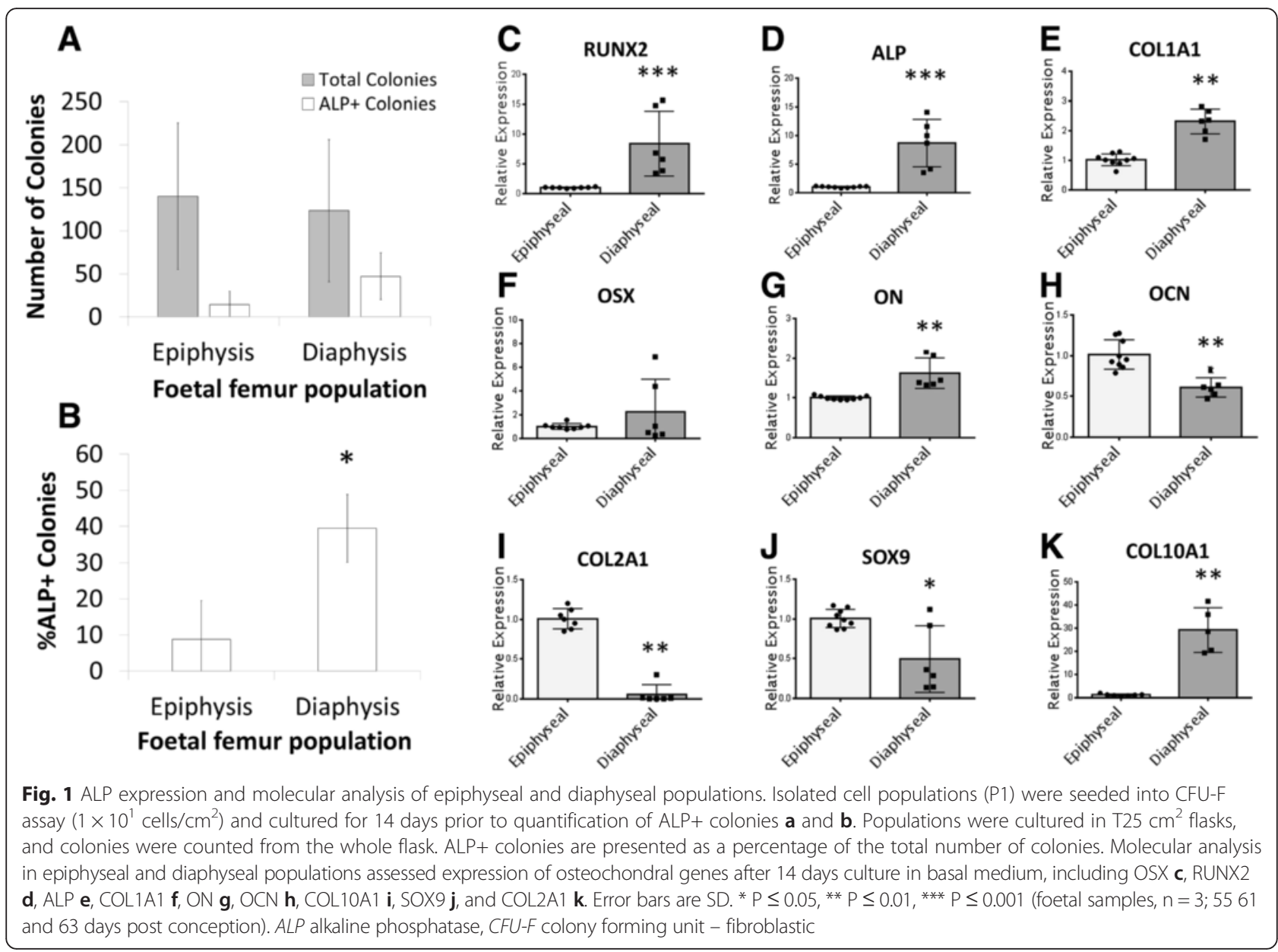

blue stained proteoglycan/mucopolysaccharide deposition) (Fig. 2c).

\section{D characterisation of epiphyseal and diaphyseal populations in vitro}

Diaphyseal 3D pellets exhibited significant $(\mathrm{P} \leq 0.05)$ upregulation of osteogenic genes including ALP (2.9 fold), COL1A1 (1.8) and RUNX2 (3.8 fold) compared with epiphyseal 3D pellets (Fig. 3a to c). Results were similar to those observed in monolayer cultures under basal conditions; however, no significant differences were observed in ON expression between epiphyseal and diaphyseal pellets (Fig. 3d), and neither OCN nor OSX were expressed (data not shown). Although expression of the chondrogenic gene COL2A1 was similar to that in monolayer cultures under basal conditions with a three-fold downregulation in diaphyseal pellets (Fig. 3e), no significant difference in SOX9 expression (Fig. 3e) was observed, and COL10A1 expression was reversed with a 2.5 fold downregulation in diaphyseal pellets (Fig. 3f).

Histological analysis revealed greater collagen deposition following differentiation culture compared to basal conditions (Fig. 4). However, both basal and differentiation culture exhibited both COL1A1 and COL2A1 deposition in epiphyseal and diaphyseal pellets. Interestingly, only epiphyseal pellets cultured in chondrogenic media exhibited SOX9 expression and osteoid formation. In addition, only diaphyseal pellets, independent of culture medium, exhibited mineralised tissue formation.

\section{Ex vivo differentiation capacity in epiphyseal and diaphyseal cell populations}

In marked contrast to control defects with no implants which remained empty (Additional file 3: Figure S2), all defects implanted with cell pellets exhibited new tissue formation (Fig. 5). Epiphyseal defects exhibited proteoglycanrich tissue, whilst diaphyseal defects exhibited collagen deposition, independent of pellet type. Both epiphyseal (Fig. 5b) and diaphyseal pellets (Fig. 5a) demonstrated new matrix deposition relative to the implantation site, possibly due to local inductive signalling cues. Birefringence imaging showed that fibre alignment within new collagen deposits was comparable to that in native mineralised tissue (Fig. 5a). 


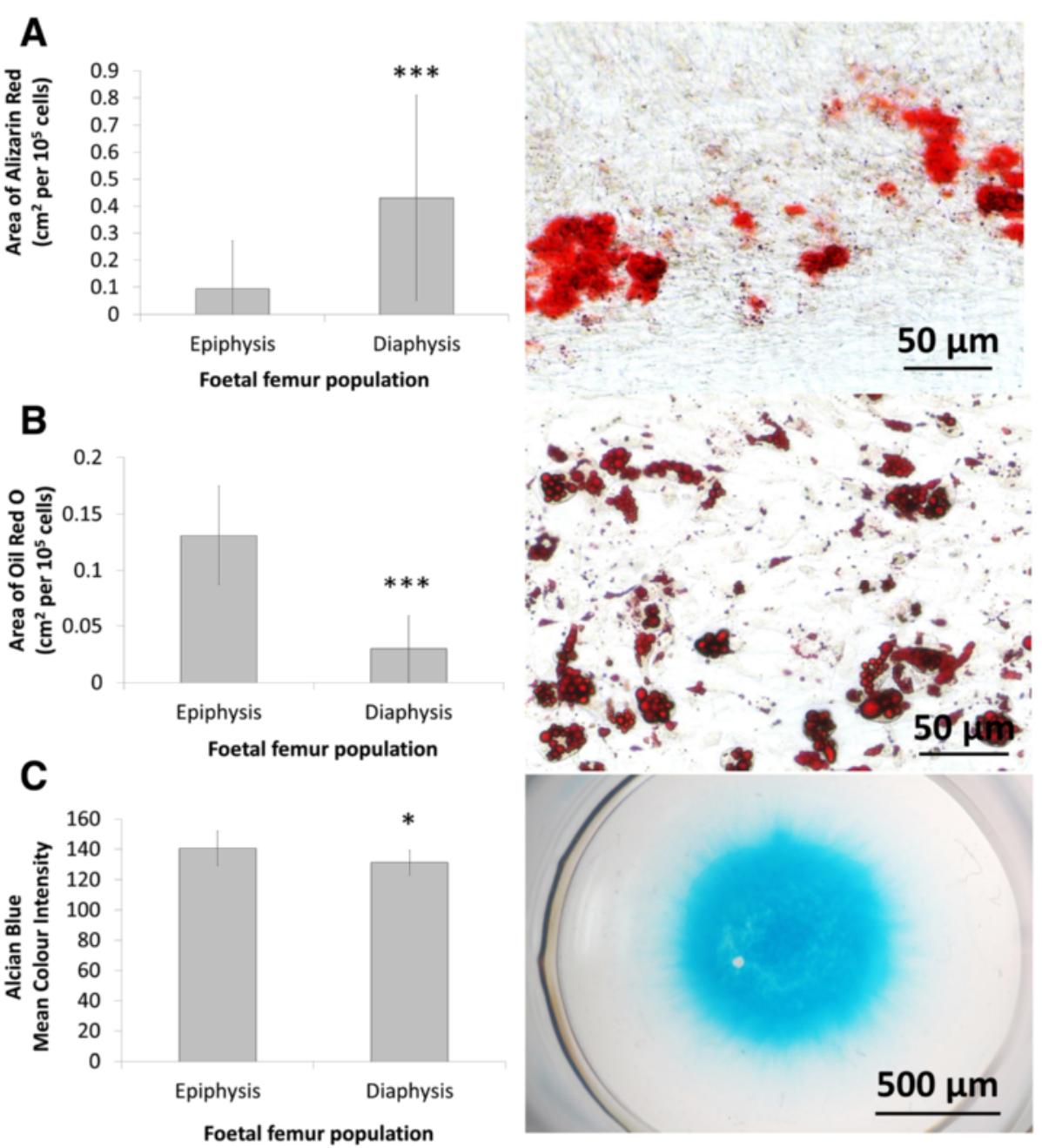

Fig. 2 Multi-lineage differentiation potential of epiphyseal and diaphyseal populations. Monolayer cultures (P2) were seeded at $1 \times 10^{3} \mathrm{cell} / \mathrm{cm}^{2}$, treated with osteogenic and adipogenic (rosiglitazone) medium for 14 days and stained with Alizarin red $\mathbf{a}$ and Oil Red $\mathrm{O}$ b, respectively. Micromass cultures $\left(2.5 \times 10^{5}\right.$ cells per pellet) were treated with chondrogenic medium for 14 days and stained with Alcian blue $\mathbf{c}$. Error bars are SD. * $\mathrm{P} \leq 0.05$, ** $\mathrm{P} \leq 0.01$, *** $\mathrm{P} \leq 0.001$ (foetal samples, $\mathrm{n}=3 ; 53,54$ and 63 days post conception)

\section{Characterisation of foetal femur cell populations isolated} by Stro-1 immuno-selection

\section{Human foetal femur development and Stro-1 expression}

During development between 47 and 69 days post conception (age range of acquired samples in this study), human foetal femurs significantly increase in size with mineralised bone collar formation between 53 and 54 days (white arrows) and marrow invasion between 59 and 67 days (Additional file 5: Figure S4). White arrows point at the bone collar. Interestingly, Stro-1 expression in the femur loosely correlated with these developmental stages (Additional file 6: Figure S5). Early Stro-1 expression was observed around 47 days post conception prior to bone collar formation. Once bone collar formation began, Stro-1 expression was again observed between 55 and 61 days. Expression was not observed following marrow invasion.

\section{D characterisation of Stro-1 immuno-selected cell populations}

Stro-1 expression was observed in monolayer cultures over five serial passages, with a rapid reduction in Stro-1 expression after passage 6 and loss of expression after passage 7 (Additional file 7: Figure S6). No change in colony formation capacity over serial passage was observed (Fig. 6a). However, ALP+ colony formation capacity significantly $(\mathrm{P} \leq 0.01)$ decreased over serial passage (Fig. 6b). Loss of ALP+ colony formation capacity appeared to correlate with significantly $(\mathrm{P} \leq 0.01)$ increased population doubling rate; however, correlation was not specifically assessed (Fig. 6c). Interestingly, ALP activity appeared unchanged over serial passage (Fig. 6d), but significantly $(\mathrm{P} \leq 0.001)$ increased following osteogenic culture (Fig. 6e). Significantly ( $\mathrm{P} \leq 0.001)$ enhanced calcium deposition and nodule formation was observed in both unsorted and Stro- 

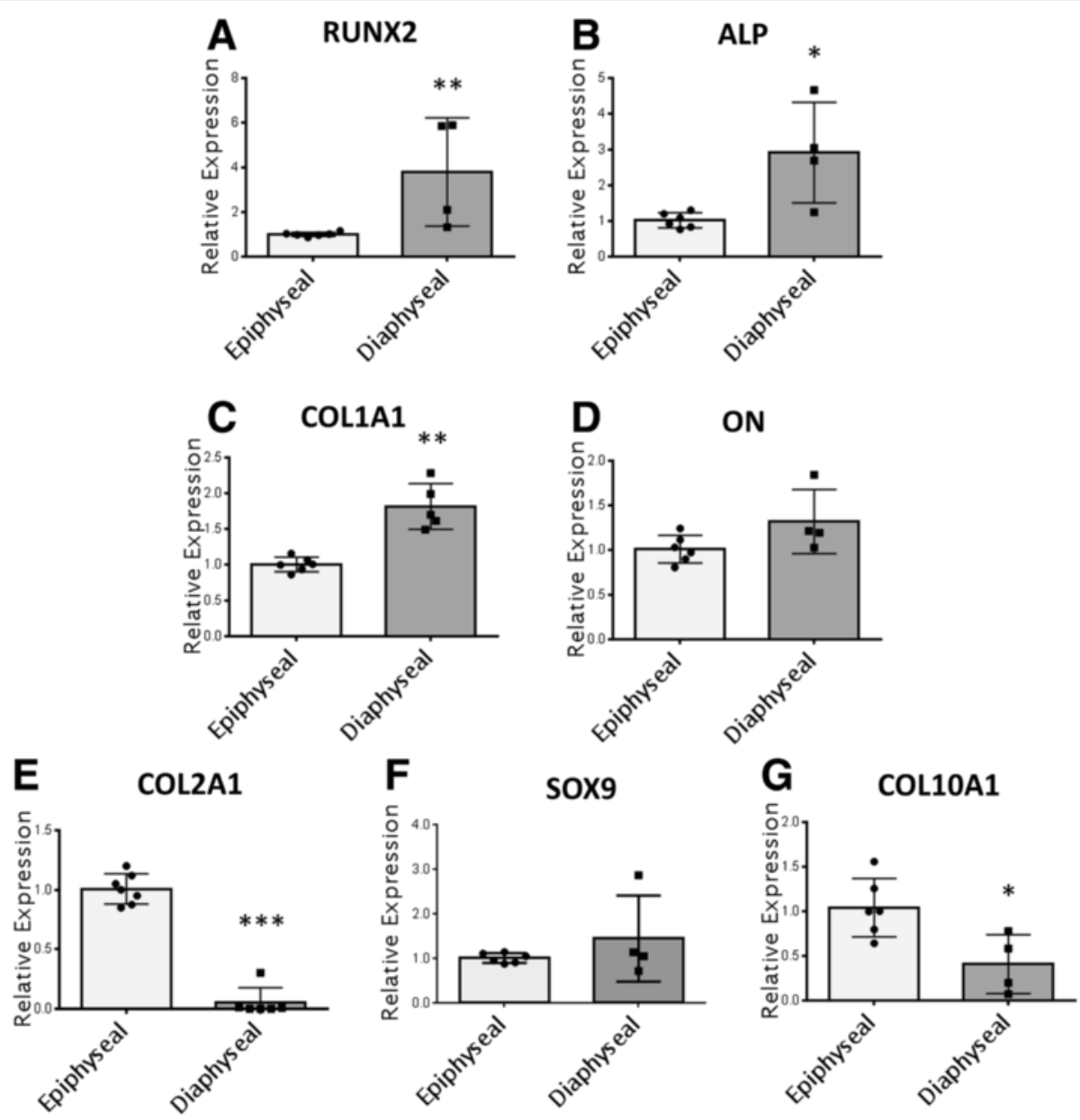

Fig. 3 Molecular analysis of gene expression in epiphyseal and diaphyseal populations cultured as 3D pellets. Pellets $\left(2.5 \times 10^{5}\right.$ cells per pellet) were cultured in basal medium for 21 days prior to analysis of osteochondral genes including RUNX2 $\mathbf{a}$, ALP b, COL1A1 c, ON d, COL $10 A 1 \mathbf{e}$, SOX9 $\mathbf{f}$ and COL2A1 $\mathbf{g}$. Error bars are SD. ${ }^{*} P \leq 0.05,{ }^{* *} P \leq 0.01$ (foetal samples, $n=3 ; 55,56$ and 63 days post conception)

1 immuno-selected populations following osteogenic compared to basal culture (Fig. 6f). Stro-1 immuno-selected populations exhibited significantly $(\mathrm{P} \leq 0.001)$ increased nodule formation even in the absence of osteogenic induction. Both populations exhibited significantly increased $(\mathrm{P} \leq 0.001)$ lipid formation following adipogenic culture, but Stro-1 immuno-selected populations exhibited significantly $(P \leq 0.001)$ higher lipid formation compared to unsorted populations (Fig. 6g). Proteoglycan deposition significantly $(\mathrm{P} \leq 0.001)$ increased equally in both unsorted and Stro-1 immuno-selected populations following chondrogenic culture (Fig. 6h).

In comparison to adult Stro-1 immuno-selected populations which are known to exhibit decreased Stro-1 expression following in vitro expansion, foetal Stro-1 immuno-selected populations exhibited phenotype stability over several passages [60]. Furthermore, multi-lineage in vitro differentiation potential was shown to correlate with Stro-1 expression over early (P2) and late (P6) passage (Additional file 8: Figure S7). Osteogenic and chondrogenic differentiation were observed without induction, highlighting a preference towards these lineages. In basal cultures, adipogenic differentiation was observed at early (P2) but not late (P6) passage.

\section{Ex vivo differentiation capacity in Stro-1 immuno-selected cell populations}

Unsorted pellets exhibited negligible new matrix formation in both epiphyseal and diaphyseal defects (Fig. 7). In marked contrast, Stro-1 immuno-selected pellets exhibited collagen deposition in diaphyseal defects. Newly deposited collagen fibre alignment was similar to that of native mineralised tissues. New matrix formation in epiphyseal defects was reminiscent of diaphyseal tissue rather than epiphyseal tissue. Birefringence imaging revealed collagen alignment similar to that of native bone collar in Stro-1 immuno-selected pellets implanted in epiphyseal defects. Differentiation capacity and matrix deposition in unsorted and Stro-1 immuno-selected foetal populations were similar to that observed in adult populations 


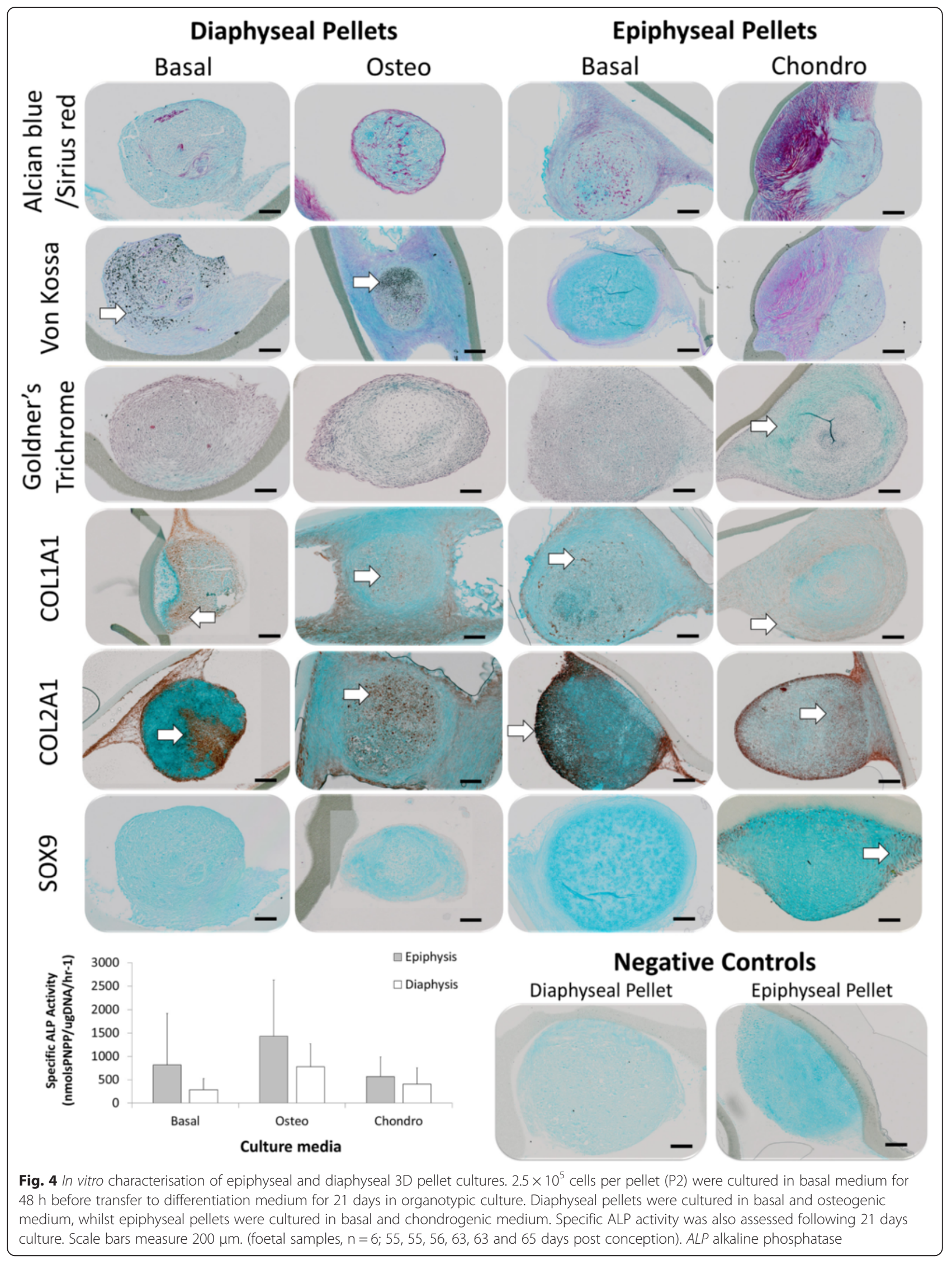




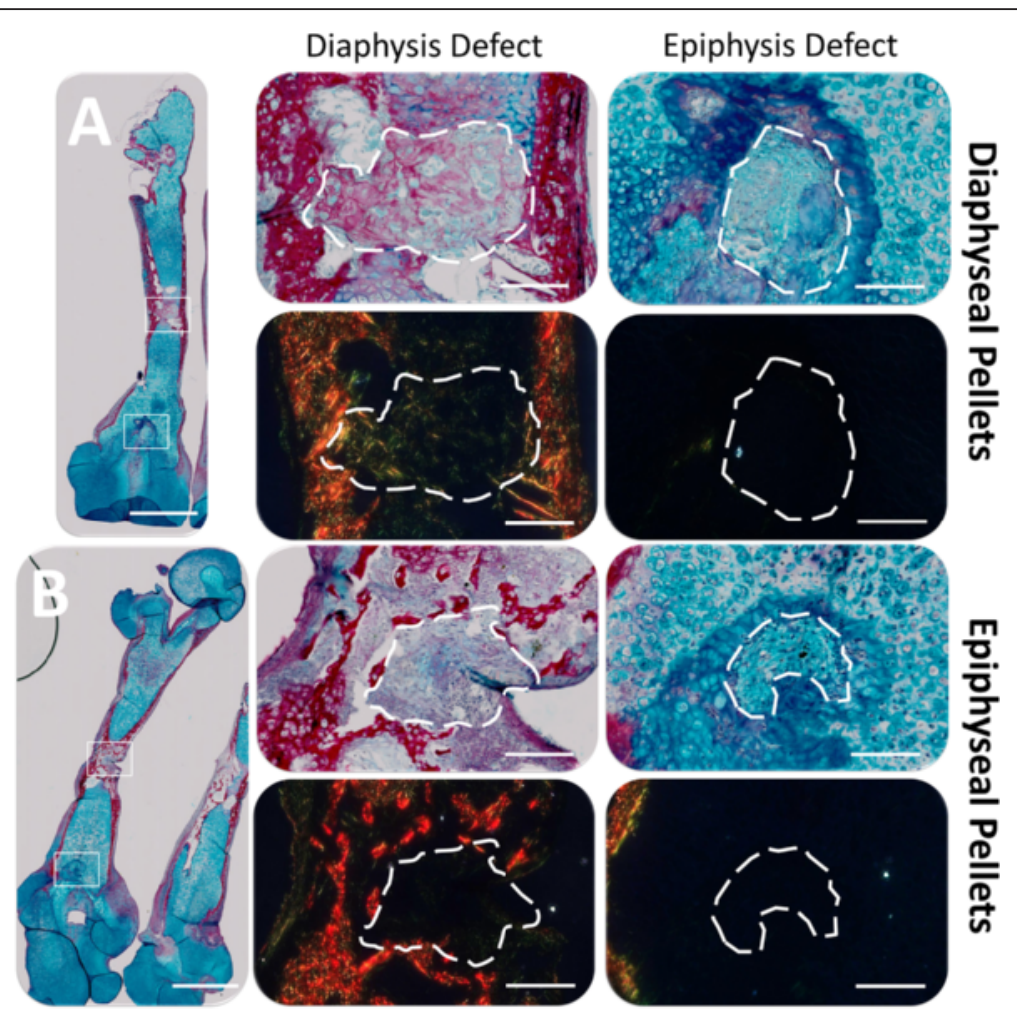

Fig. 5 Ex vivo bone defect regeneration following implantation of diaphysis-derived $\mathbf{a}$ and epiphysis-derived $\mathbf{b} 3 \mathrm{D}$ cell pellets. Pellets $\left(1.5 \times 10^{4}\right.$ cells per pellet [P2]) were implanted in drill defects (300 $\mu$ m diameter) at both epiphyseal and diaphyseal locations on an embryonic day 11 chick femur, and incubated for 10 days in organotypic culture in basal medium. Femora were fixed, embedded in wax, sectioned and stained with Alcian blue/ Sirius red and imaged for birefringence using polarising filters. Highly aligned collagen fibres in mineralised bone appeared red. Scale bars measure $1 \mathrm{~mm}$ (low magnification images) and $100 \mu \mathrm{m}$ (high magnification images). (foetal samples, n=4; 54, 59, 63 and 65 days post conception)

(Additional file 9: Figure S8). Adult unsorted pellets exhibited minimum collagen deposition in both epiphyseal and diaphyseal defects, whilst adult Stro-1 pellets exhibited new collagen deposition with fibre alignment similar to that in native bone collar.

\section{Discussion}

The current study has characterised both regional and immuno-selected skeletal cell populations derived from human foetal femora. These populations offer tools for both in vitro and ex vivo interrogation of the biological mechanisms controlling skeletal development and bone formation. Understanding these mechanisms using foetal populations as a developmental paradigm will inevitably inform successful in vivo tissue engineering strategies leading to improved bone formation and defect reparation downstream. Careful dissection through the metaphyses resulted in two regional populations, epiphyseal and diaphyseal cells. Distinction between the epiphysis and diaphysis is not clear as the metaphysis is a transitional zone between the two regions. The authors are aware that a simplified dissection approach to cell isolation may lead to cross-contamination of epiphyseal and diaphyseal populations. Indeed, further investigation revealed the presence of a shared sub-population of cells between both regions exhibiting Stro-1 expression, indicating a potential SSC source. Nevertheless, this study shows the osteochondral differentiation potential of these distinct foetal femur populations and their contribution to skeletal development and repair by means of a bone defect model.

$2 \mathrm{D}$ in vitro characterisation revealed an osteogenic phenotype in diaphyseal populations (enhanced bone nodule formation) and a distinct chondrogenic phenotype in epiphyseal populations (enhanced proteoglycan and mucopolysaccharide deposition) indicative of the SSC maturation stages expected within these respective regions. Early markers of osteogenic differentiation capacity (ALP, COL1A1, RUNX2 and OSX) were observed to be higher in diaphyseal populations. As would be expected with early osteogenic differentiation, expression of late markers such as OCN, was not increased. However, an alternative mid-late osteogenic marker ON was significantly increased indicating the presence of a subpopulation of diaphyseal cells that had become fully differentiated and functional osteoblasts in the 14 day culture period. It is important to note here that although OCN expression was not significantly increased in diaphyseal populations, expression was still observed 

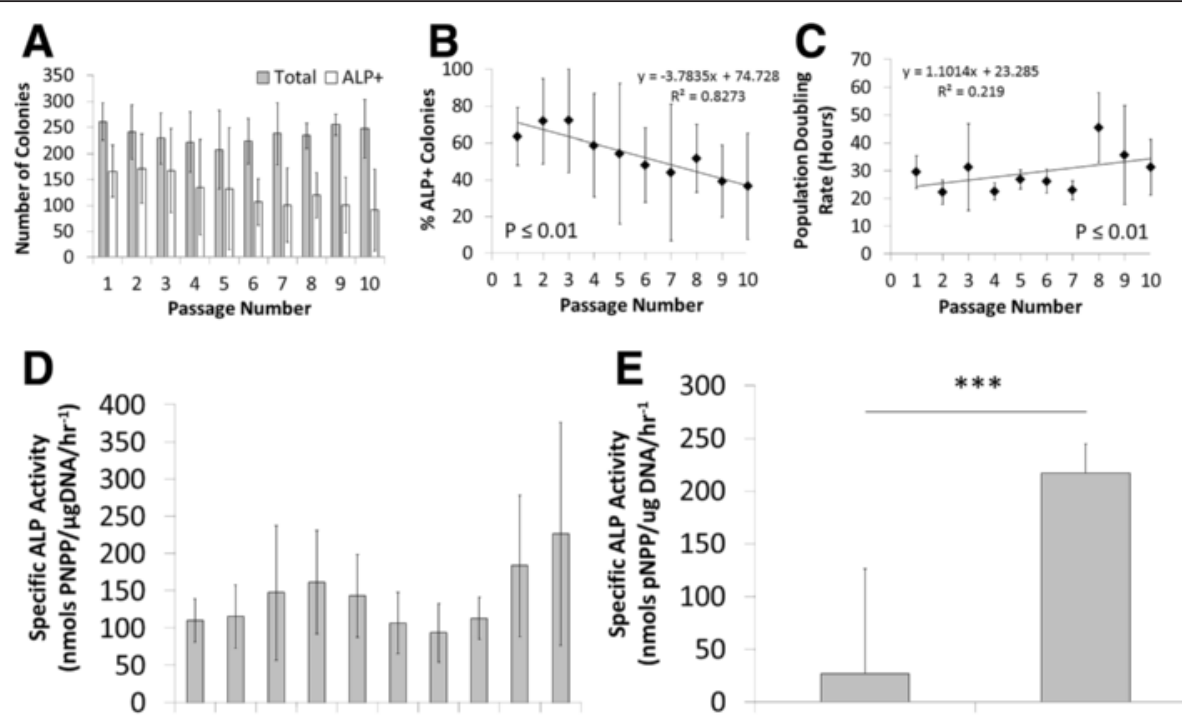

$\begin{array}{llllllllll}1 & 2 & 3 & 4 & 5 & 6 & 7 & 8 & 9 & 10\end{array}$

Passage Number

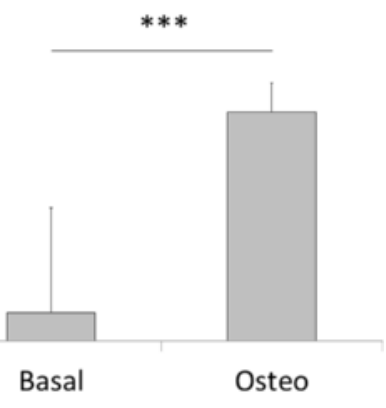

Differentiation Media
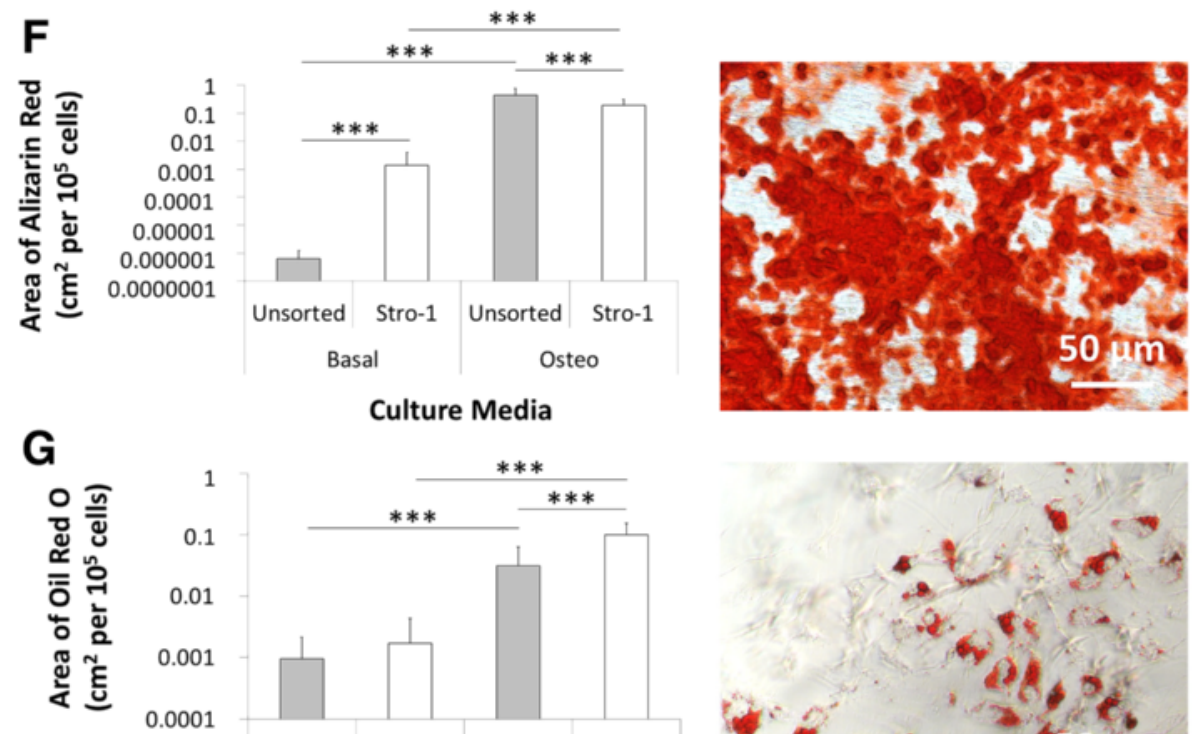

Culture Media

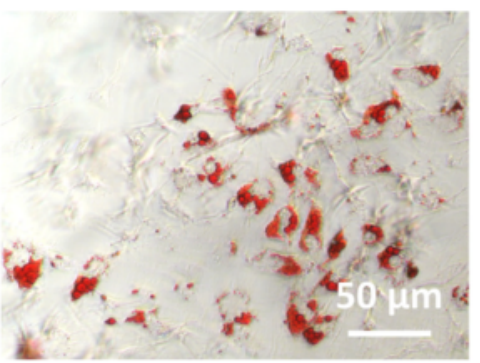

H
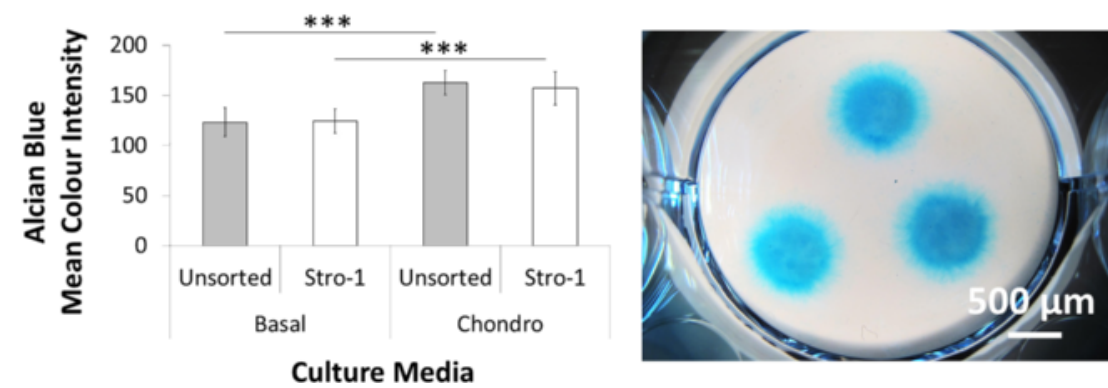

Fig. 6 (See legend on next page.) 
(See figure on previous page.)

Fig. 6 In vitro characterisation of Stro-1 immuno-selected populations. Isolated cell populations were seeded into CFU-F assay $\left(1 \times 10^{2}\right.$ cells/cm $\left.{ }^{2}\right)$ over serial passage (P1 to P10) and cultured for 14 days in T25 $\mathrm{cm}^{2}$ flasks before fixation in $85 \%$ ethanol and staining for ALP expression a ( $n=4$; 55, 55, 55 and 56 days of age foetal samples). ALP+ colonies are presented as a percentage of the total number of colonies counted $\mathbf{b}$. Population doubling rate (c, foetal samples, $n=6 ; 55,55,55,55,56$ and 56 days post conception), a measurement of proliferation, and specific ALP activity (d, foetal samples, $n=4 ; 55,55,56$ and 56 days of age post conception) were also assessed over serial passage in monolayer cultures seeded at $1 \times 10^{3}$ cells $/ \mathrm{cm}^{2}$ (P2). Specific ALP activity was also assessed in cell populations (P2) following 14 days culture in basal or osteogenic medium (e, foetal samples, $\mathrm{n}=3 ; 55,56$, and 59 days (Stro-1); 55,55 and 61 days (unsorted) of age post conception). Additional monolayer cultures $\left(1 \times 10^{3} \mathrm{cells} / \mathrm{cm}^{2}, \mathrm{P} 2\right)$ were treated with osteogenic and adipogenic (rosiglitazone) medium for 14 days, and stained with Alizarin red $\mathbf{f}$ and Oil Red O g, respectively. Micromass cultures $\left(2.5 \times 10^{5}\right.$ cells per pellet, P2) were treated with chondrogenic medium for 14 days and stained with Alcian blue $\mathbf{h}$. Control monolayers were cultured in basal medium. Representative images were of Stro-1 immuno-selected cultures in differentiation media. Error bars are SD. *** $P \leq 0.001$ (foetal samples, $n=3 ; 55,56$ and 59 days (Stro-1); 55, 55 and 61 days (unsorted) of age post conception). ALP alkaline phosphatase

confirming the presence of mature osteoblasts. Expression profiles of early (increased SOX9 and COL2A1) and late (reduced COL10A1) chondrogenic genes in epiphyseal populations indicated elevated early chondrocyte differentiation. Higher COL10A1 expression in diaphyseal populations indicated the presence of hypertrophic chondrocytes, important in the formation of mineralised cartilage. Similar trends were observed following 3D pellet culture for osteogenic genes including ALP, COL1A1 and RUNX2. However, unlike monolayer cultures, expression of mid to late osteogenic genes was not observed indicating the absence of terminal differentiation. Indeed, expression of chondrogenic gene SOX9 was not significantly different between epiphyseal and diaphyseal populations suggesting cartilaginous and pre-osteoid formation was dominant. In support, COL10A1 expression was reduced in diaphyseal populations highlighting the lack of hypertrophic chondrocytes important for mineralisation. Critically, the similarities and differences observed may be due to separate maturation stages within

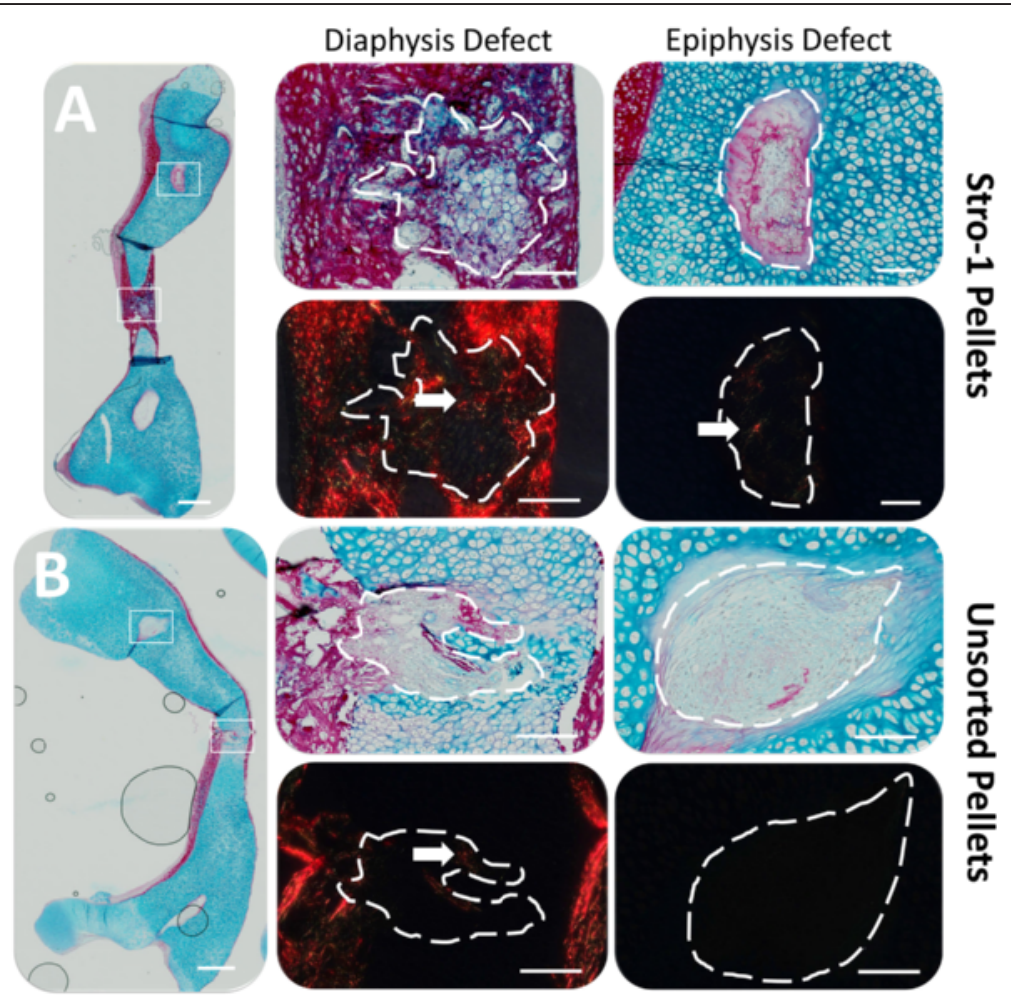

Fig. 7 Ex vivo bone defect regeneration following implantation of Stro-1 a and unsorted $\mathbf{b} 3 \mathrm{D}$ pellets. Pellets $\left(1.5 \times 10^{4}\right.$ cells per pellet [P2]) were implanted in drill defects (300 $\mathrm{\mu m}$ diameter) at both epiphyseal and diaphyseal locations on an embryonic day 11 chick femur, and incubated for 10 days in organotypic culture in basal medium. Femora were fixed, embedded in wax, sectioned and stained with Alcian blue/Sirius red and imaged for birefringence using polarising filters. Highly aligned collagen fibres in mineralised bone appeared red. Scale bars measure $1 \mathrm{~mm}$ (low magnification images) and $100 \mu \mathrm{m}$ (high magnification images). (foetal samples, $\mathrm{n}=3 ; 55,55$ and 56 days (Stro-1); 55,55 and 61 days (unsorted) of age post conception) 
the respective populations. As such, further investigation over serial passage would be required to assess the stability of epiphyseal and diaphyseal population phenotypes.

Histological analysis revealed mineralisation in diaphyseal pellets and SOX9 expression in epiphyseal pellets. Counter-intuitively, COL1A1 and COL2A1 deposition was observed in both epiphyseal and diaphyseal pellets, although a shared sub-population and rapid developmental background offers some explanation as to why both regional derived populations exhibited expression of both osteogenic and chondrogenic markers. It is important to note that cross-contamination of populations during isolation may also explain the dual expression of COL1A1 and COL2A1. Both cell origin and implantation site correlated with defect regeneration capacity; epiphyseal and diaphyseal populations exhibited differentiation plasticity dependent upon their environment, suggesting the presence of a shared inducible subpopulation of progenitor cells.

Developmental stage-dependent Stro-1 expression (adult SSC marker [5, 65, 66]) was observed in human foetal femora in the epiphyses and the diaphysis, supporting the presence of a shared SSC sub-population. Interestingly, Stro-1 immuno-selected populations exhibited phenotype stability over prolonged passage, unlike their adult Stro-1 counterparts which lose expression after a single in vitro passage. Encouragingly, Stro-1 expression correlated with multi-lineage differentiation potential at early (P2) and late (P6) passage. Expression also appeared to correlate with decreased cell proliferation and ALP+ colony formation, indicating possible emergence of a clonogenic fibroblastic phenotype, often observed in prolonged in vitro cultures [67].

Without exogenous induction, Stro-1 immuno-selected populations exhibited strong differentiation potential towards the osteogenic lineage; this may explain why Stro-1 implants displayed only bone-like tissue formation. Unsorted populations demonstrated similar differentiation potential to Stro-1 immuno-selected populations. However, this did not translate to functional tissue regeneration, evidenced by reduced new collagen and proteoglycan deposition. This may be due to the lack of inductive signals in vivo for unsorted populations, whereas Stro-1 immunoselected populations represent cell populations already committed to the osteochondral differentiation path. Foetal Stro-1 pellets demonstrated similar differentiation capacity to their adult Stro-1 counterparts; both exhibited osteogenic differentiation potential independent of implantation site. This may be due to underlying mechanisms and environmental factors in 3D pellet cultures that drive differentiation along the osteogenic lineage.

Interestingly, both regional populations and Stro-1 immuno-selected populations isolated from human foetal femora clearly demonstrated capacity for multi-lineage differentiation and formation of new matrix reminiscent of bone, cartilage and fat. However, to fully determine their capacity for functional tissue regeneration and, therefore, their application as an investigative tool, further in vivo experimentation is required.

\section{Conclusions}

The current study demonstrates isolation of distinct cell populations from human foetal femora according to anatomical location and immuno-selection. Regionally derived populations from the epiphyses and diaphysis offer potential cell sources for routine chondrogenic and osteogenic differentiation, respectively. A shared SSC sub-population, however, affords both epiphyseal and diaphyseal populations a degree of differentiation plasticity. Stro- 1 enrichment isolated an SSC alternative to their conventional adult counterparts. However, to fully understand the tissue regenerative capacity of these distinct populations, further investigation is required to assess functional tissue formation in vivo. The work presented here shows that foetal femur-derived populations offer investigative tools with which to understand biological mechanisms involved in skeletal development and their translation to regenerative medicine. Furthermore, ex vivo assessment of these populations provides a novel system with which to screen potential tissue engineering strategies prior to time consuming (and expensive) in vivo studies.

\section{Additional files}

Additional file 1: Figure S1. Human foetal femur following dissection and removal of surrounding soft tissues $(\mathbf{A})$ and an $\mathrm{x}$-ray radiograph (B). Red lines depict metaphyseal regions. White lines depict the epiphyseal and diaphyseal regions. (foetal sample; 65 days post conception). (JPEG 831 kb)

Additional file 2: Table S1. Forward and reverse primer sequences used for quantitative RT-PCR analysis. (JPEG $1068 \mathrm{~kb}$ )

Additional file 3: Figure S2. Control defect generation on embryonic day 11 chick femora in organotypic culture. Drill defects $(300 \mu \mathrm{m}$ diameter) were created along the length of the femur and restricted to the epiphyses and diaphysis prior to pellet implantation. Control sham defects were created and chick femora were organotypically cultured for 10 days. (JPEG $1137 \mathrm{~kb}$ )

Additional file 4: Figure S3. Correlation between seeded cell number and 3D pellet diameter. Human foetal femur derived cells were suspended in basal medium and centrifuged at 1,000 rpm for 4 min to form pellets. 3D pellets were subsequently cultured in basal medium for $48 \mathrm{~h}$. Pellets were formed from a range of cell numbers $\left(1 \times 10^{4}\right.$ to $1 \times 10^{6}$ cells). Following pellet formation and incubation, pellets were imaged by light microscopy and their diameter recorded. Error bars show SD. (foetal samples, $n=3 ; 54$, 54 and 63 days of age post conception). (JPEG $381 \mathrm{~kb}$ )

Additional file 5: Figure S4. Development of human foetal femora and bone collar formation. Human foetal femora covering a range of developmental stages from 47 to 69 days post conception were fixed, embedded in wax, sectioned and stained with Alcian blue/Sirius red. Femora increase significantly in size and exhibit both mineralisation and marrow cavity formation. Scale bars measure $100 \mu \mathrm{m}$ (high magnification images) and $500 \mu \mathrm{m}$ (low magnification images). (JPEG 3785 kb)

Additional file 6: Figure S5. Development of human foetal femora and Stro-1 expression. Human foetal femora covering a range of developmental 
stages from 47 to 69 days post conception were fixed, embedded in wax sectioned and Stro-1 immuno-labelled. Stro-1 appeared dependent on developmental stage with expression around 47 days and 59 to 61 days post conception, largely restricted to the diaphysis (depicted as bright brown stain). High magnification images of the femur at 47 days clearly show Stro-1 expression in the diaphysis but not in the epiphysis. Negative controls were stained without the primary antibody. Scale bars in epiphysis and diaphysis individual images measure $100 \mu \mathrm{m}$. Scale bars in the femur overview images measure $500 \mu \mathrm{m}$. (JPEG $3030 \mathrm{~kb}$ )

Additional file 7: Figure S6. Maintenance of Stro-1 expression following MACS isolation over serial passage in vitro. Isolated cells were seeded into 12-well plates $\left(1 \times 10^{3} \mathrm{cells} / \mathrm{cm}^{2}\right)$ at each consecutive passage (P1 to P10), and cultured for three to five days (for cell adhesion and proliferation) before fixation in 4 \% PFA. Monolayers labelled for Stro-1 expression, counterstained with DAPI were imaged by fluorescence microscopy. Left windows show fluorescence images and right windows show the same images in brightfield. Scale bars measure $50 \mu$ m. (foetal samples, $n=3 ; 55$, 55 and 56 days post conception). (JPEG $1864 \mathrm{~kb}$ )

Additional file 8: Figure S7. Differentiation potential of Stro-1 immuno-selected populations from human foetal femora over extended passage. Isolated cells were seeded $\left(1 \times 10^{3} \mathrm{cell} / \mathrm{s} / \mathrm{cm}^{2}\right)$ as monolayer cultures and expanded to P2 (top two rows) and P6 (bottom two rows) before differentiation in osteogenic and adipogenic (indomethacin) medium for 14 and 28 days, respectively. Micromass pellets $\left(2.5 \times 10^{5}\right.$ cells per pellet) were formed in basal medium for $1 \mathrm{~h}$ before culture in chondrogenic medium for 21 days. Control cultures were treated with basal medium. Osteogenesis was assessed by ALP expression, chondrogenesis by proteoglycan deposition (Alcian blue staining), and adipogenesis by lipid deposition (Oil Red $O$ staining). (foetal samples, $n=3 ; 55,55$ and 55 days post conception). (JPEG $3635 \mathrm{~kb}$ )

Additional file 9: Figure S8. Ex vivo bone defect regeneration following implantation of Stro-1 immuno-selected and unsorted cell pellets derived from adult human bone marrow. Pellets $\left(1.5 \times 10^{4}\right.$ cells per pellet (P2)) were implanted in drill defects ( $300 \mu \mathrm{m}$ diameter) at both epiphyseal and diaphyseal locations on an embryonic day 11 chick femur, and incubated for 10 days in organotypic culture in basal medium. Femora were fixed, embedded in wax, sectioned and stained with Alcian blue/Sirius red and imaged for birefringence using polarising filters. Highly aligned collagen fibres in mineralised bone red. Scale bars measure $100 \mu \mathrm{m}$. ( $\mathrm{n}=5$; F54, F67, F71, M60 and M78 (Stro-1); F52, M46, M67, M75 and M78 (unsorted)) $M=$ male; $F=$ female. (JPEG $1702 \mathrm{~kb}$ )

\section{Abbreviations}

2D: Two dimensional; 3D: Three dimensional; A/S: Alcian blue/Sirius red ALP: Alkaline phosphatase; Asc: Ascorbate-2-phosphate; BSA: Bovine serum albumin; CFU-F: Colony forming unit-fibroblastic; DAPI: 4',6-diamidino-2phenylindole; Dex: Dexamethasone; EDTA: Ethylenediaminetetraacetic acid; FCS: Foetal calf serum; HA-PLA: Hydroxyapatite-loaded poly - lactic acid; HBMSC: Human bone marrow stromal cell; IBMX: Isobutyl-1-methylxanthine; ITS: Insulin/transferrin/sodium selenite; MACS: Magnetic activated cell sorting; MSC: Mesenchymal stem cell; OCN: Osteocalcin; ON: Osteonectin; OSX: Osterix; P1/P2/P6: Passage 1/2/6; PBS: Phosphate buffered saline; PCR: Polymerase chain reaction; PFA: Paraformaldehyde;

PTFE: Polytetrafluoroethylene; RT-qPCR: Reverse transcription-quantitative PCR; SD: Standard deviation; SSC: Skeletal stem cell; UV: ultraviolet; aMEM: Modified Eagle's medium - alpha.

\section{Competing interests}

The authors declare that they have no competing interests.

\section{Authors' contributions}

DG conceived of the study, performed experimental work, data collection, data analysis, and drafted the manuscript. KC performed molecular analysis and helped with manuscript writing. JMK helped design and perform ex vivo studies with chick femora, data analysis, and drafted the manuscript. DIW provided and prepared foetal tissues for all experiments, and helped with manuscript writing. ROCO conceived of the study and oversaw its design and coordination, and helped to draft the manuscript. All authors read and approved the final manuscript.

\section{Acknowledgements}

The authors would like to thank Dr. Kate L. Wright and Anne Chad, University of Southampton, for their help with the collection and isolation of foetal tissues. We would also like to thank Ms Joanna Greenhough for her technical help with early experiments investigating Stro-1 expression in human foetal femora. Special thanks to Dr. Larry Fisher, $\mathrm{NIH}$, for provision of COL1A1 antibody. Finally, thanks to Dr. Jon N. Beresford, University of Bath, for his gift of Stro-1 hybridoma. This work was supported by the BBSRC (LOLA grant BB/G010579/1).

\section{Author details}

'Bone and Joint Research Group, Centre for Human Development, Stem Cells and Regeneration, Human Development and Health, University of Southampton, School of Medicine, Institute of DevelopmentalSciences, Mail Point 887, Southampton General Hospital, Tremona Road, Southampton SO16 6YD, UK. ${ }^{2}$ Centre for Human Development, Stem Cells and Regeneration, Human Development and Health, University of Southampton, School of Medicine, Institute of Developmental Sciences, Mail Point 887, Southampton General Hospital, Tremona Road, Southampton SO16 6YD, UK. ${ }^{3}$ University Hospital Southampton NHS Foundation Trust, Tremona Road, SO16 6YD Southampton, UK.

Received: 25 November 2014 Revised: 25 November 2014 Accepted: 25 November 2015 Published online: 18 December 2015

\section{References}

1. Rose FR, Oreffo RO. Bone tissue engineering: hope 'vs' hype. Biochem Biophys Res Commun. 2002;292(1):1-7.

2. Bianco P, Robey PG, Saggio I, Riminucci M. Mesenchymal stem cells in human bone marrow (skeletal stem cells): a critical discussion of their nature, identity, and signficance in incurable skeletal disease. Hum Gene Ther. 2010;21 (9):1057-66.

3. Seong JM, Kim BC, Park JH, Kwon IK, Mantalaris A, Hwang YS. Stem cells in bone tissue engineering. Biomed Mater. 2010;5(6):062001.

4. Kwan MD, Slater BJ, Wan DC, Longaker MT. Cell-based therapies for skeletal regenerative medicine. Hum Mol Genet. 2008;17(R1):R93-8.

5. Mirmalek-Sani SH, Tare RS, Morgan SM, Roach HI, Wilson DI, Hanley NA, et al. Characterization and multipotentiality of human fetal femur-derived cells: implications for skeletal tissue regeneration. Stem Cells. 2006;24(4):1042-53.

6. Gothard D, Tare RS, Mitchell PD, Dawson JI, Oreffo RO. In search of the skeletal stem cell: isolation and separation strategies at the macro/micro scale for skeletal regeneration. Lab Chip. 2011;11(7):1206-20.

7. Schroeder JE, Mosheiff R. Tissue engineering approaches for boen repair: concepts and evidence. Injury. 2011;42(6):609-13.

8. Gamie Z, Tran GT, Vyzas G, Korres N, Heliotis M, Mantalaris A, et al. Stem cells combined with bone graft in skeletal tissue engineering. Expert Opin Biol Ther. 2012;12(6):713-29.

9. Dawson Jl, Kanczler J, Tare RS, Kassem M, Oreffo RO. Concise review: bridging the gap: bone regeneration using skeletal stem cell-based strategies-where are we now? Stem Cells. 2014;32(1):35-44.

10. Owen M, Friedenstein AJ. Stromal stem cells: marrow-derived osteogenic precursors. Ciba Found Symp. 1988;136:42-60.

11. Panetta NJ, Gupta DM, Quarto N, Longaker MT. Mesenchymal cells for skeletal tissue engineering. Panminerva Med. 2009:51(1):25-41.

12. Parekkadan B, Milwid JM. Mesenchymal stem cells as therapeutics. Annu Rev Biomed Eng. 2010;12:87-117.

13. Bork S, Horn P, Castoldi M, Hellwig I, Ho AD, Wagner W. Adipogenic differentiation of human mesenchymal stromal cells is down-regulated by microRNA-369-5p and up-regulated by microRNA-371. J Cell Physiol. 2011; 226(9):2226-34.

14. Hudson JE, Mills RJ, Frith JE, Brooke G, Jaramillo-Ferrada P, Wolvetang EJ, et al. A defined medium and substrate for expansion of human mesenchymal stromal cell progenitors that enriches for osteo- and chondrogenic precursors. Stem Cells Dev. 2011;20(1):77-87.

15. Tsai CC, Huang TF, Ma HL, Chiang ER, Hung SC. Isolation of mesenchymal stem cells from shoulder rotator cuff: potential source for muscle and tendon repair. Cell Transplant. 2013;22(3):413-22.

16. Pittenger MF, Mackay AM, Beck SC, Jaiswal RK, Douglas R, Mosca JD, et al. Multilineage potential of adult human mesenchymal stem cells. Science. 1999;284(5411):143-7. 
17. de la Garza-Rodea AS, van der Velde-van Dijke L, Boersma H, Goncalves MA, van Bekkum DW, de Vries AA, et al. Myogenic properties of human mesenchymal stem cells derived from three different sources. Cell Transplant. 2012;21(1):153-73.

18. Aurich H, Sgodda M, Kaltwasser P, Vetter M, Weise A, Leihr T, et al. Hepatocyte differentiation of mesenchumal stem cells from human adipose tissue in vitro promotes hepatic integration in vivo. Gut. 2009;58(4):570-81.

19. Zeng R, Wang LW, Hu ZB, Guo WT, Wei JS, Lin H, et al. Differentiation of human bone marrow mesenchymal stem cells into neuron-like cells in vitro. Spine. 2011;36(13):997-1005.

20. Tormin A, Brune JC, Olsson E, Valcich J, Neuman U, Olofsson T, et al. Characterization of bone marrow-derived mesenchymal stromal cells (MSC) based on gene expression profiling of functionally defined MSC subsets. Cytotherapy. 2009;11(2):114-28

21. Pevsner-Fischer M, Levin S, Zipori D. The origins of mesenchymal stromal cell heterogeneity. Stem Cell Rev. 2011;7(3):560-8.

22. Zannettino AC, Paton S, Arthur A, Khor F, Itescu S, Gimble JM, et al. Multipotential human adipose-derived stromal cells exhibit a perivascular phenotype in vitro and in vivo. J Cell Physiol. 2008;214(2):413-21.

23. Agha-Hosseini F, Jahani MA, Jahani M, Mirzaii-Dizgah I, Ali-Moghaddam K. In vitro isolation of stem cells derived from human dental pulp. Clin Transplant. 2010;24(2):E23-8.

24. Lorenz K, Sicker M, Schmelzer E, Rupf T, Salvetter J, Schultz-Siegmund M, et al. Multilineage differentiation potential of human dermal skin-derived fibroblasts. Exp Dermatol. 2008;17(11):925-32.

25. Bueno DF, Kerkis I, Costa AM, Martins MT, Kobayashi GS, Zucconi E, et al. New source of muscle-derived stem cells with potential for aveolar bone reconstruction in cleft lip and/or palate patients. Tissue Eng A. 2009;15(2):427-35.

26. Harvanova D, Tothova T, Sarissky M, Amrichova J, Rosocha J. Isolation and characterization of synovial mesenchymal stem cells. Folia Biol. 2011;57(3):119-24

27. Koyama N, Okubo Y, Nakao K, Osawa K, Fujimura K, Bessho K. Pluripotency of mesenchymal cells derived from synovial fluid in patients with temporomandibular joint disorder. Life Sci. 2011;89(19-20):741-7.

28. Semenov OV, Koestenbauer S, Riegel M, Zech N, Zimmermann R, Zisch AH, et al. Multipotent mesenchymal stem cells from human placenta: critical parameters for isolation and maintenance of stemness after isolation. Am J Obstet Gynecol. 2010;202(2):193. e1-e13.

29. Zhang X, Hirai M, Cantero S, Ciubotariu R, Dobrila L, Hirsch A, et al. Isolation and characterisation of mesenchymal stem cells from human umbilical cord blood: reevaluation of critical factors for successful isolation and high ability to proliferate and differentiate to chondrocytes as compared to mesenchymal stem cells from bone marrow and adipose tissue. J Cell Biochem. 2011;112(4):1206-18.

30. In't Anker PS, Scherjon SA, Kleijburg-van der Keur C, Noort WA, Claas FH, Willemze $R$, et al. Amniotic fluid as a novel source of mesenchymal stem cells for therapeutic transplantation. Blood. 2003;102(4):1548-9.

31. Marongiu F, Gramignoli R, Sun Q, Tahan V, Miki T, Dorko K, et al. Isolation of amniotic mesenchymal stem cells. Curr Protoc Stem Cell Biol. 2010;Chapter 1:Unit 1E.5.

32. Keating A. Mesenchymal stromal cells: new directions. Cell Stem Cell. 2012; 10(6):709-16.

33. Bianco P. Back to the future: moving beyond "mesenchymal stem cells". J Cell Biochem. 2011;112(7):1713-21. doi:10.1002/jcb.23103.

34. Bianco P. "Mesenchymal" stem cells. Annu Rev Cell Dev Biol. 2014;30:677-704. doi:10.1146/annurev-cellbio-100913-013132.

35. Bianco P, Robey PG, Simmons PJ. Mesenchymal stem cells: revisiting history, concepts and assays. Cell Stem Cell. 2008;2(4):313-9.

36. Bianco P, Kuznetsov SA, Riminucci M, Gehron RP. Postnatal skeletal stem cells. Methods Enzymol. 2006;419:117-48.

37. Bianco P, Sacchetti B, Riminucci M. Stem cells in skeletal physiology and endocrine diseases of bone. Endocr Dev. 2011;21:91-101. doi:10.1159/ 000328138.

38. Robey PG, Kuznetsov SA, Riminucci M, Bianco P. Skeletal ("mesenchymal") stem cells for tissue engineering. Methods Mol Med. 2007;140:83-99.

39. Abdulrazzak H, Moschidou D, Jones G, Guillot PV. Biological characteristics of stem cells from foetal, cord blood and extraembryonic tissues. J R Soc Interface. 2010;7 Suppl 6:S698-706.

40. Gucciardo L, Lories R, Ochsenbein-Kolble N, Done E, Zwijsen A, Deprest J. Fetal mesenchymal stem cells: isolation, properties and potential use in perinatology and regenerative medicine. BJOG. 2009;116(2):166-72.
41. Montjovent MO, Bocelli-Tyndall C, Scaletta C, Scherberich A, Mark S, Martin I, et al. In vitro characterization of immune-related properties of human fetal bone cells for potential tissue engineering applications. Tissue Eng A. 2009; 15(7):1523-32.

42. Marcus AJ, Woodbury D. Fetal stem cells from extra-embryonic tissues: do not discard. J Cell Mol Med. 2008;12(3):730-42

43. Gronthos S, Zannettino AC, Hay SJ, Shi S, Graves SE, Kortesidis A, et al. Molecular and cellular characterisation of highly purified stromal stem cells derived from human bone marrow. J Cell Sci. 2003;116(9):1827-35.

44. Simmons PJ, Torok-Storb B. Identification of stromal cell precursors in human bone marrow by a novel monoclonal antibody, STRO-1. Blood. 1991; 78(1):55-62.

45. Tare RS, Khan F, Tourniaire G, Morgan SM, Bradley M, Oreffo RO. A microarray approach to the identification of polyurethanes for the isolation of human skeletal progenitor cells and augmentation of skeletal cell growth. Biomaterials. 2009;30(6):1045-55.

46. Zannettino AC, Paton S, Kortesidis A, Khor F, Itescu S, Gronthos S. Human multipotential mesenchymal/stromal stem cells are derived from a discrete subpopulation of STRO-1 bright/CD34/CD45-/Glycophorin-A-bone marrow cells. Haematologica. 2007;92(12):1707-8.

47. Gronthos S, Graves SE, Ohta S, Simmons PJ. The STRO-1+ fraction of adult human bone marrow contains the osteogenic precursors. Blood. 1994; 84(12):4164-73.

48. Gronthos S, Simmons PJ. The growth factor requirements of STRO-1positive human bone marrow stromal precursors under serum-deprived conditions in vitro. Blood. 1995;85(4):929-40.

49. Yang XB, Webb D, Blaker J, Boccaccini AR, Maquet V, Cooper C, et al. Evaluation of human bone marrow stromal cell growth on biodegradable polymer/bioglass composites. Biochem Biophys Res Commun. 2006;342(4):1098-107.

50. Yang X, Walboomers XF, van den Beucken JJ, Bian Z, Fan M, Jansen JA. Hard tissue formation of STRO-1-selected rat dental pulp stem cells in vivo. Tissue Eng A. 2009:15(2):367-75.

51. Krattinger N, Applegate LA, Biver E, Pioletti DP, Caverzasio J. Regulation of proliferation and differentiation of human fetal bone cells. Eur Cells Mater. 2011;21:46-58.

52. Montjovent MO, Burri N, Mark S, Federici E, Scaletta C, Zambelli PY, et al Fetal bone cells for tissue engineering. Bone. 2004;35(6):1323-33.

53. Xu Y, Mirmalek-Sani SH, Lin F, Zhang J, Oreffo RO. Adipocyte differentiation induced using nonspecific siRNA controls in cultured human mesenchymal stem cells. RNA. 2007:13(8):1179-83.

54. Chuang CY, Shahin K, Lord MS, Melrose J, Doran PM, Whitelock JM. The cartilage matrix molecule components produced by human foetal cartilage rudiment cells within scaffolds and the role of exogenous growth factors. Biomaterials. 2012;33(16):4078-88.

55. El-Serafi AT, Wilson DI, Roach HI, Oreffo RO. Developmental plasticity of human foetal femur-derived cells in pellet culture: self assembly of an osteoid shell around a cartilaginous core. Eur Cells Mater. 2011;21:558-67.

56. Montjovent MO, Mark S, Mathieu L, Scaletta C, Scherberich A, Delabarde C, et al. Human fetal bone cells associated with ceramic reinforced PLA scaffolds for tissue engineering. Bone. 2008;42(3):554-64.

57. Kanczler JM, Mirmalek-Sani SH, Hanley NA, Ivanov AL, Barry JJ, Upton C, et al. Biocompatibility and osteogenic potential of human fetal femurderived cells on surface selective laser sintered scaffolds. Acta Biomater. 2009;5(6):2063-71

58. Tenorio DM, Scaletta C, Jaccoud S, Hirt-Burri N, Pioletti DP, Jaques B, et al. Human fetal bone cell in delivery systems for bone engineering. J Tissue Eng Regen Med. 2011;5(10):806-14.

59. Montjovent MO, Mathieu L, Hinz B, Applegate LL, Bourban PE, Zambelli PY, et al. Biocompatibility of bioresorbable poly(L-lactic acid) composite scaffolds obtained by supercritical gas foaming with human fetal bone cells. Tissue Eng. 2005;11(11-12):1640-9.

60. Stewart K, Walsh S, Screen J, Jefferiss CM, Chainey J, Jordan GR, et al. Further characterization of cells expressing STRO-1 in cultures of adult human bone marrow stromal cells. J Bone Miner Res. 1999;14(8):1345-56.

61. Mirmalek-Sani SH, Stokes PJ, Tare RS, Ralph EJ, Inglis S, Hanley NA, et al. Derivation of a novel undifferentiated human foetal phenotype in serum-free cultures with BMP-2. J Cell Mol Med. 2009;13(9B):3541-55.

62. Howard D, Partridge K, Yang X, Clarke NM, Okubo Y, Bessho K, et al. Immunoselection and adenoviral genetic modulation of human osteoprogenitors: in vivo bone formation on PLA scaffolds. Biochem Biophys Res Commun. 2002;299(2):208-15. 
63. Kanczler JM, Smith EL, Roberts CA, Oreffo RO. A novel approach for studying the temporal modulation of embryonic skeletal development using organotypic bone cultures and microcomputed tomography. Tissue Eng Part C Meth. 2012:18(10):747-60.

64. Smith EL, Kanczler JM, Roberts CA, Oreffo RO. Developmental cues for bone formation from parathyroid hormone and parathyroid hormone-related protein in an ex vivo organotypic culture system of embryonic chick femora. Tissue Eng Part C Meth. 2012;18(12):984-94.

65. Dennis JE, Carbillet JP, Caplan Al, Charbord P. The STRO-1+ marrow cell population is multipotential. Cells Tissues Organs. 2002;170(2-3):73-82.

66. Williams EL, White K, Oreffo RO. Isolation and enrichment of Stro-1 immunoselected mesenchymal stem cells from adult human bone marrow. Methods Mol Biol. 2013;1035:67-73.

67. Wagner W, Horn P, Castoldi M, Diehlmann A, Bork S, Saffrich R, et al. Replicative senescence of mesenchymal stem cells: a continuous and organized process. PLoS One. 2008;3(5):e2213.

Submit your next manuscript to BioMed Central and we will help you at every step:

- We accept pre-submission inquiries

- Our selector tool helps you to find the most relevant journal

- We provide round the clock customer support

- Convenient online submission

- Thorough peer review

- Inclusion in PubMed and all major indexing services

- Maximum visibility for your research

Submit your manuscript at www.biomedcentral.com/submit
Biomed Central 